\title{
Citric acid as feed additive in diet of rabbit- effect on growth performance
}

\author{
M. J. Uddin, K. M. S. Islam, A. Reza and R. Chowdhury* \\ Department of Animal Nutrition, Bangladesh Agricultural University, Mymensingh-2202, Bangladesh, "E-mail: \\ rakhich03_bau@yahoo.com
}

\begin{abstract}
The experiment was conducted for a period of 56 days using 24 growing rabbits (4 to 6 weeks old) to evaluate the effect of citric acid (CA) on the growth performance. Concentrate mixture was fortified by $0,0.5,1.0$ and $1.5 \%$ CA to 4 different groups of rabbit considering 6 in each. Green grass and concentrate mixture were supplied on ad-libitum basis. Growth rate increased 5, 8 and $12 \%$ respectively in $0.5,1.0$ and $1.5 \%$ CA supplemented groups (P>0.05). Total dry matter (DM) intake decreased numerically due to increased level of CA whereas, growth velocity increased with increased level of CA. Insignificant difference observed in terms of feed conversion ratio (FCR-DM intake/weight gain) among different groups but improved 6,16 , and $8 \%$ respectively in $0.5,1.0$ and 1.5\% CA offering groups. Over all numerically better performance obtained due to addition of CA in rabbit diet. So, it may be concluded that the CA up to level of $1.5 \%$ in diet may have positive effect on growth performance of growing rabbit.
\end{abstract}

Keywords: Citric acid, Growing rabbit, Performance

\section{Introduction}

Antimicrobial feed additives are used worldwide so far in animal husbandry to improve the economy and ecology of animal production by increasing growth rate, decreasing feed expenditure and diminishing the risk of disease. Ban on antibiotics as growth promoters in European Union, and the resulting pressures on meat exporters around the world, has increased interest in organic acids (formic, fumaric, citric, lactic, propionic etc.). Those approved at EU-level as a preservative, because it exert their antimicrobial action both in the feed and in the gastro-intestinal tract of the animal through feeding (Zdzislaw, 2005). Its antimicrobial activity increases with increasing concentrations and length of carbon chain as well as due to decreasing pH (Hinton et al., 2000). The effect of organic acids in animal diets can be addressed for suppressing pathogenic growth and improving digestion, absorption and mucosal immunity (Zdzislaw, 2005). Positive effect of citric acid (CA) on growth performance of broiler chicks and pig is reported by several researchers (Afsharmanesh and Pourreza, 2005, Shen-HuiFang et al. 2005, Jozefiak and Rutkowski, 2005, Boling et al. 2000), but there is a scarce of information on the effect of CA in rabbit. Therefore, the present research was focused on growth performance and nutrient digestibility of growing rabbit fed citric acid fortified diet.

\section{Materials and Methods}

A total number of 24 newly weaned (4 to 6 weeks age) healthy crossbred New Zealand White growing rabbits were selected and housed individually in steel cages measuring $1.95 \mathrm{~m} \times 1.80 \mathrm{~m} \times 1.27 \mathrm{~m}$ in dimension. J-shaped screened metal feeder and $250 \mathrm{ml}$ bottle waterers with steel straw were provided in each cage. Rabbits were distributed randomly into 4 treatment groups in a Completely Randomized Design (CRD) having 6 rabbits in each. A concentrate mixture composed of $35 \%$ maize, $25 \%$ wheat, 10 $\%$ soybean meal, $15 \%$ til oil cake, $14 \%$ wheat bran, $0.5 \%$ common salt, $0.25 \%$ premix and $0.15 \%$ DLmethionine containing $16.91 \% \mathrm{CP}, 2703 \mathrm{ME}$ (Kcal/kg DM), $0.37 \%$ calcium and $0.17 \%$ total phosphorus (according to NRC, 1994), which was further fortified by $0,0.5,1.0$ and $1.5 \%$ CA on top of the ration to make them different diets. Concentrate mixture, green grass (Dhal grass) and fresh clean water was offered as ad libitum basis.

Growth performance of the experimental rabbit was studied for 56 days and a conventional digestibility trial was conducted during last 7 days of the feeding trial. Feeds left over were recorded and deducted from the feed supplied to determine feed intake weekly. Total amount of faeces voided was recorded against each animal and $10 \%$ of the feces was collected, dried in the sun and stored in the refrigerator by keeping in polythene bag for chemical analysis. Rabbits were weighed individually at the beginning of the experiment and weekly interval. The feed conversion ratio (FCR-DM intake/weight gain) was calculated and growth velocity (GV) was also calculated using following formula (Handa et al., 1995).

$\mathrm{GV}=\frac{\mathrm{FW}-\mathrm{IW}}{\mathrm{IW}}$; where, $\mathrm{FW}=$ Final body weight; IW = Initial body weight 
Feed sample, feces sample and ingesta of GI tract were collected and mixed with water separately and $\mathrm{pH}$ value was measured by $\mathrm{pH}$ meter. At the end of the trial all of the rabbits were weighted and slaughtered for the measurement of carcass characteristics.

Samplse from feed, green grass and feces were analyzed for proximate composition following the method of AOAC (1990). Collected data were analyzed by using "SPSS 11.5" statistical program to compute analysis of variance (ANOVA). Duncan's Multiple Range Test (Duncan, 1955) was done to compare the treatment means at $5 \%$ level of significance (Steel and Torrie, 1980).

\section{Results and Discussion}

\section{Growth Performance}

The effect of different levels of CA on performance of growing rabbit is presented in Table 1. After 56 days trial, highest body weight was found in $1.5 \%$ CA supplemented group. Numerically highest growth rate was recorded in $1.5 \%$ CA supplemented group $(13.99 \mathrm{~g} / \mathrm{d})$ and lowest in control $(12.50 \mathrm{~g} / \mathrm{d})$. Addition of CA improved weight gain were almost 5,8 and $12 \%$ due to inclusion of $0.5,1.0$ and $1.5 \%$ respectively that is daily weight gain increased with the linear increasing level of CA in the rabbit diets. By creating acidic conditions, CA makes the nutrients more available and prevents the growth of harmful microorganism, which monitors better performance. The findings is in harmony with Abdel-Fattah et al. (2008) who reported that, dietary citric acid, acetic acid and lactic acid improved the live body weight of broilers $(P<0.05)$ as compared to control. The current result also supported by the result of several researchers (Radcliffe et al. 1998), although in other species but simulated here due to scarce of information on the effect of CA in rabbit. The result also correspond the highest growth velocity $(1.39 \mathrm{~g})$ for $1.5 \%$ CA added group, whereas $0,0.5$ and $1.0 \%$ CA supplemented group showed 1.26, 1.30 and $1.35 \mathrm{~g}$ respectively.

Table 1. Performance of growing rabbit fed at different level of Citric Acid

\begin{tabular}{|l|c|c|c|c|}
\hline \multirow{2}{*}{ Parameter } & \multicolumn{4}{|c|}{ Treatment (\% Citric acid) } \\
\cline { 2 - 5 } & 0 & 0.5 & 1.0 & 1.5 \\
\hline Initial weight $(\mathrm{g})$ & $590 \pm 49$ & $595 \pm 148$ & $590 \pm 173$ & $590 \pm 147$ \\
\hline Final weight $(\mathrm{g})$ & $1290 \pm 115$ & $1330 \pm 139$ & $1343 \pm 164$ & $1373 \pm 127$ \\
\hline Total weight gain $(\mathrm{g})$ & $700 \pm 50$ & $735 \pm 80$ & $753 \pm 42$ & $783 \pm 51$ \\
\hline Growth rate $(\mathrm{g} / \mathrm{d})$ & $12.5 \pm 10$ & $13.13 \pm 10$ & $13.45 \pm 10$ & $13.99 \pm 10$ \\
\hline Total DM intake $(\mathrm{g})$ & $3511 \pm 146$ & $3438 \pm 220$ & $3341 \pm 53$ & $3338 \pm 30$ \\
\hline Daily DM intake $(\mathrm{g})$ & $62.70 \pm 30$ & $61.40 \pm 40$ & $59.67 \pm 10$ & $59.60 \pm 50$ \\
\hline Growth velocity & $1.26 \pm 0.46$ & $1.30 \pm 0.38$ & $1.35 \pm 0.37$ & $1.39 \pm 0.41$ \\
\hline FCR & $5.02 \pm 0.16$ & $4.73 \pm 0.70$ & $4.45 \pm 0.26$ & $4.62 \pm 0.27$ \\
\hline
\end{tabular}

N. B. Values of different variables under different program indicates mean \pm SE; The value in parenthesis indicates the relation with the value of control.

Mild doses of CA increase the palatability of feed as a result feed intake also increase, whereas higher doses increase sourness and decrease feed intake (Moghadam et al. 2006, Atapathu and Nelligaswatta 2005). Data presented in Table 1 showed that, daily DM intake decreased by 2,5 and $5 \%$ indifferent groups due to supplementation of $0.5,1.0$ and $1.5 \%$ CA respectively comparison to control. This result agrees with the result of other researchers (Falkowski and Aherne 1983, Radeki et al. 1988). Best FCR (4.45) observed in $1.0 \% \mathrm{CA}$ added group, but differences was not significant $(P>0.05)$. Improvement of FCR occurred 6,16 and $8 \%$ due to addition of $0.5,1.0$ and $1.5 \% \mathrm{CA}$ in concentrate mixture. This result agrees by other researchers also worked in poultry and rabbit (Afsharmanesh and Pourreza, 2005, Atapattu and Nelligaswatta, 2005, Abdel-Azeem et al. 2000). 


\section{Digestibility}

Dietary acidification increases gastric proteolysis and protein, amino acid digestibility. Furthermore, longer and thicker villi, better feed efficiency, feed digestion and absorption than that of control were observed in CA supplemented broiler (Abdel-Fattah et al., 2008). The digestibility of different nutrient is shown in Table 2. The result revealed that, digestibility of CP increased with increased level of CA, but only numerical. Moreover, improvement of CF digestibility was recorded as 13,3 and $5 \%$ in $0.5,1.0$ and $1.5 \%$ CA offering groups consequently. Being an organic acid, citric acid may weaken the structure of crude fiber thus making crude protein and phytate associated with them more susceptible for enzymatic digestion and facilitate the nutrient digestibility.

Digestibility of EE was highest $(P<0.05)$ in $1.5 \%$ CA group and lowest in $1.0 \%$ CA group. The highest digestibility of NFE was recorded in control and lowest for $1.0 \%$ CA group. The digestibility of CP, CF and EE was increased slightly due to addition of $C A$ in the diet. Other work revel that nutrient digestibility increased due to supplementation of CA in growing rabbit (Abdel-Azeem et al. 2000), whereas Falkowaski and Aherne (1984), that is the inclusion of fumaric or citric acid in the diets had no significant effect on the apparent digestibility of protein and DM.

Table 2. Effect of citric acid supplementation on digestibility

\begin{tabular}{|l|c|c|c|c|}
\hline \multirow{2}{*}{ Parameters } & \multicolumn{4}{|c|}{ Treatment (\% Citric acid) } \\
\cline { 2 - 5 } & 0 & 0.5 & 1.0 & 1.5 \\
\hline CP & $55.95 \pm 8$ & $55.79 \pm 15$ & $56.21 \pm 6$ & $58.30 \pm 4$ \\
\hline CF & $34.40 \pm 10$ & $38.72 \pm 8$ & $35.46 \pm 13$ & $35.99 \pm 7$ \\
\hline EE & $45.86^{\mathrm{a}} \pm 10$ & $40.94^{\mathrm{a}} \pm 12$ & $40.13^{\mathrm{a}} \pm 13$ & $66.96^{\mathrm{b}} \pm 1$ \\
\hline NFE & $74.87 \pm 2$ & $65.86 \pm 5$ & $65.54 \pm 7$ & $65.68 \pm 5$ \\
\hline
\end{tabular}

N. B. Values of different variables under different program indicates mean $\pm \mathrm{SE} ;{ }^{\mathrm{ab}}$ Mean values within the same row with different superscripts are significantly different $(P<0.05)$.

\section{The $\mathrm{pH}$ of concentrate feed, parts of gastrointestinal tract and feces}

The antimicrobial activity of any organic acid is related to the reduction of $\mathrm{pH}$, as well as their ability to dissociate because they are lipid soluble in the undissociated form, in which they are able to enter the microbial cell. The $\mathrm{pH}$ level in specific areas of the gastro intestinal tract (GIT) is a factor which establishes a specific microbial population, and also affects the digestibility and absorptive value of most nutrients. Several researchers studied on this matter (Jozefiak and Rutkowski, 2005, Andrys et al., 2003, Boling et al., 2001). So, in this experiment the $\mathrm{pH}$ of concentrate feed, different parts of gastro intestinal tract and feces of rabbit fed CA supplemented diet was observed (Table 3) and compared with control group. The $\mathrm{pH}$ of concentrate feed was $6.2,5.9,5.7$ and 5.56 for $0,0.5,1.0$ and $1.5 \% \mathrm{CA}$ addition respectively $(\mathrm{P}<0.01)$, where $\mathrm{pH}$ of control diet decreased chronologically with the addition of increasing levels of CA. The $\mathrm{pH}$ of the stomach decreased 3,7 and $16 \%$ relative to control group due to addition of $0.5,1.0$ and $1.5 \%$ CA respectively. Biochemical reaction and buffering capacity of saliva in digestive tract minimized the variation of $\mathrm{pH}$.

Table 3. pH of ration, different parts of gastro intestinal tract and feces of rabbit fed different level of CA

\begin{tabular}{|l|c|c|c|c|}
\hline \multirow{2}{*}{ Parameters } & \multicolumn{4}{|c|}{ Treatment (\% Citric acid) } \\
\cline { 2 - 5 } & 0 & 0.5 & 1.0 & 1.5 \\
\hline Concentrate feed & $6.2^{\mathrm{a}} \pm 0$ & $5.9^{\mathrm{b}} \pm 0$ & $5.7^{\mathrm{c}} \pm 0$ & $5.6^{\mathrm{d}} \pm 0$ \\
\hline Stomach & $4.0 \pm 0.5$ & $3.9 \pm 0.3$ & $3.71 \pm 0.3$ & $3.33 \pm 0.2$ \\
\hline Small intestine & $6.6 \pm 0.5$ & $6.6 \pm 0.4$ & $6.3 \pm 0.3$ & $6.5 \pm 0.2$ \\
\hline Caecum & $5.7 \pm 0.2$ & $5.7 \pm 0.2$ & $5.7 \pm 0.4$ & $5.7 \pm 0.1$ \\
\hline Faeces & $7.3 \pm 0.3$ & $7.1 \pm 0.1$ & $7.1 \pm 0.3$ & $7.1 \pm 0.1$ \\
\hline
\end{tabular}

N. B. Values of different variables under different program indicates average \pm SE; ${ }^{\text {abcd }}$, Mean values within the same row with different superscripts are significantly different $(P<0.05)$; the value in parenthesis indicates the relation with the value of control. 
The $\mathrm{pH}$ of the caecum as well as feces remains similar for all groups. The variation in $\mathrm{pH}$ observed in prepared diet, started minimization in stomach and completed in small intestine and therefore insignificant variation was found in small intestine and caecum. Ultimately caecum and faeces identified as similar $\mathrm{pH}$ value although feed had different $\mathrm{pH}$. This was similar to the findings of Radcliffe et al., (1998) and Scipioni et al., (1979).

However, weight gain of domestic rabbit increased with the increased level of CA in concentrate diet, as well as when roughage was considered in addition to concentrate then FCR found better in CA supplemented group. Better growth performance of CA fed group compared to control might be due to better efficiency in feed digestion and absorption as well as reduction of dietary $\mathrm{pH}$ leads to the reduction of pathogenic microbes from gastro intestinal tract and improve nutrient absorption by rabbit. So, it might be possible to improve growth performance of growing rabbit by using CA up to $1.5 \%$ in the diet.

\section{References}

Abdel-Azeem, F., Y. M. El-Hommosany, Nematallah and Ali, G.M. 2000. Effect of citric acid in diets with different starch and fiber levels on productive performance and some physiological traits of growing rabbits. Egypt. J. Rabbit Sci., 10: 121-145.

Abdel-Fattah, S.A., El-Sanhoury, M.H., El-Mednay, N.M. and Abdul-Azeem, F. 2008. Thyroid activity of broiler chicks fed supplemental organic acids. International Journal of Poultry Science, 7(3): 215-222.

Afsharmanesh, M. and Pourreza, J. 2005. Effect of calcium, citric acid, ascorbic acid vitamin D3 on the efficacy of microbial phytase in broiler starters fed wheat-based diets on performance, bone mineralization and ileal digestibility. Int. J. Poul Sci., 4: 418-424.

Andrys, R., Klecker, D., Zeman, L. and Marecek, E. 2003. The effect of changed pH values of Feed in isophosphoric diets on chicken broiler performance. Czech- Journal of Animal Science, 48(5): 197-206.

AOAC. 1990. Official Method of Analysis (15 Edt). Association of Official Analytical Chemists, Washington D. C, U. S. A.

Atapattu, N.S.B.M. and Nelligaswatta, C.J. 2005. Effects of citric acid on the performance and utilization of phosphorous and crude protein in broiler chickens fed rice byproducts based diets. International Int. J. Poul Sci., 4: 990-993.

Boling, S.D., Webel, S.M., Mavromichalis, I., Parsons, C.M. and Baker, D.H. 2000. The effect citric acid on phytate phosphorous utilization in young chicks and pigs. J. Anim. Sci., 78 (3): 682-689.

Duncan, B. 1955. Multiple range test and multiple F test. Biometrics 11: 1-42.

Falkowski, J. and Aherne, F.X. 1983. Fumaric acid and citric acid as feed additives in starter pig nutrition. Agriculture and Forestry Bulletin, 122-123.

Handa, D.J., Sapra, K.L. and Shingari, B.K. 1995. Rabbits for meat production. Asian Livest. 20 (9): 99-103.

Hinton, A. Jr., Buhr, R.J. and Ingram, K.K. 2000. Reduction of Salmonella in the crop of broiler chickens subjected to feed withdrawal. Poult. Sci., 79: 1566-1570.

Jozefiak, D. and Rutkowski, A. 2005. The effect of supplementing a symbiotic, organic acids or P-glucanase to barley based diets on the performance of broiler chickens. J. Anim. Feed Sci., 14: 447-450.

Moghadam, A.N., Pourreza, J. and Samie, A.H. 2006. Effect of different levels of citric acid on calcium and phosphorus efficiencies in broiler chicks. Pakistan Journal of Biological Science, 9 (7): 1250-1256.

National Research Council. 1994. National Requirements of Poultry. 9th Rev. Edn., National Academy Press, Washington, DC. USA.

Radcliffe, J.S., Zhang, Z. and Kornegav, E.T. 1998. The effect of microbial phytase, CA and their interaction in a corn-soybean meal based diet for weaning pigs. J. Anim. Sci., 76(7): 1880-1886.

Radeki, S.V., Juhl, M.R. and Miller, E.R. 1988. Fumaric and citric acid as feed additives in starter pig diets: effect on performance and nutrient balance. J. Anim. Sci., 66(10): 2598-2605.

Scipioni, R., Zaghini, G. and Biavati, B. 1979. The use of acidified diets for early weaning piglets. Inst. Alimentazione Animale, Via S. Giacomo, Bologna, Italy., 20 (5): 73-84.

Shen-HuiFang, Han-ChuiWang and Du-Bing Wang. 2005. Effect of citric acid on production performance of Three Yellow chicken. China Poult., 27: 14-15.

Steel G.D. and Torrie, J.H. 1980. Principles and Procedure of statistics. McGrow Hill Book Company Inc., New York.

Zdzislaw, M. 2005. Organic acids as potential alternatives to antibiotic growth promoters for pigs. Advan. Pork Prod., 16: 169. 